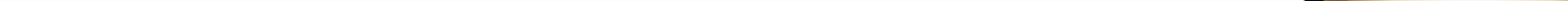




\section{Miyazakiworld: A Life in Art}

\section{Ayçin Ergin Akdaş}

Susan Napier is a professor in Japanese studies and regarded as an expert on Miyazaki

based on her seminars and her three previous books on anime. Regarding the reading experience, it is notable that she has written this biography not only for the reason of being part of her profession but also because of her fondness for the work of Miyazaki's. This book includes sixteen chapters that the first three ones are written chronologically starting from Miyazaki's infancy and process with his entering into the anime world and establishing his studio; 'Studio Ghibli.' This information about Miyazaki is provided without excluding knowledge about his movies; likewise, the following thirteen chapters concerning mainly his movies are tightly interwoven with Miyazaki's life and personality. For instance, in chapter 8, Napier demonstrates Miyazaki's keen interest in European cities through the background of 'Kiki's Delivery Service' (1989) which is about a thirteen years old witch leaving her home country to stay in a modern city for one year as all the witches do as a ritual. Traveling is a passion for Miyazaki, and we trace this passion by watching incredible city views from different parts of the world in this anime, such as the images of Stockholm and Mediterranean cities. (p. 169) Napier also states one of the main characteristics of Miyazaki movies, that could name as his signature, as using children as the lead characters of the story. Since nature and supernatural forces are the themes of most of Miyazaki movies, using 
children protagonists are inevitable for the reason of their purity in terms of making contact with nature and supernatural forces, in other words with 'others'. The otherness is a significant term here as the other could be a supernatural force - as the spirit of the forest in 'Princess Mononoke' (1997) - or could be the nature or environment itself that the modern society keeps its distance.

In most of the chapters, Napier refers to the relationship between Miyazaki and his mother. The main referring is Miyazaki's mother's illness; tuberculosis and how this reality affected his childhood in terms of having a bedded mother who could not take care of him properly and the chores he took on his back in the house as a result of this. Most of the Miyazaki movies treating this issue as such in 'My Neighbor Totoro' (1988) and 'The Wind Rises' (2013). A mother staying in the hospital due to her illness and a dying fiancee/wife because of tuberculosis are two of the main characters of these movies respectively. Getting back to the mother issue, Napier also mentions the classic 'returning to the womb' theory while analyzing 'Porco Rosso' (1992). She links the situation of having an adult male lead character preferably than a young female one, to Miyazaki's middle-age complexities at the time and uses the womb theory to explain the cove that Porco discovers for secluding himself from his complicated daily life.

This book is also so essential to pursue Japan's pre-war and post-war eras because tracking the reflections of these vital incidents with the writer certainly informs the reader about 
the historical background of Japan. We read how Japanese society -also Miyazaki- is indignant with the government and military because of their overconfidence of bombing Pearl-Harbor, and the ensuing destruction of the US invasion. Therefore, a world that preserving by unsoiled children away from adult complexities gains more importance considering from this point of view. Napier further uncovers Miyazaki's political judgments and their reflections that spectators implicitly exposed to. Using coal miners and villagers to support and protect Sheeta and Pazu in 'Laputa: Castle in the Sky' (1986), for instance, is the reflection of union days of Miyazaki's at his first place of employment.

Japan, notoriously, is famous for its two natural disasters: mighty earthquakes and tsunamis. However, these natural catastrophes do not confine themselves to their painful results. They also lead up other disasters in a chain such as in the March 2011 earthquake: an earthquake causing a tsunami, and a tsunami, causing a meltdown of the Fukushima nuclear power plant. Miyazaki was in his 50s when this disaster occurred, but he also lived the 1995 Kobe earthquake and Aum Shinrikyo incident of releasing sarin gas in Tokyo station, in the same year. According to Napier, with his 2008 production 'Ponyo,' Miyazaki foresaw the tsunami disaster as real-like because Ponyo is a girl fish would like to become a human and the village of his human boyfriend endangers by the big waves she causes through her journey to the surface. Although this is an 
overstated interpretation and kind of a mystical point of view of Napier's, it is still a compelling case in terms of showing Miyazaki's sensitivity to nature's destructive and constructive features. This thought comes into prominence with Napier's mentioning of 'Japanese awareness of nature's overwhelming power.' (p. 27)

This book presents us with an excellent opportunity to know Miyazaki; nevertheless, because of being an analysis of an artist through his art-works, it is crucial to state that it would not be so meaningful to read this biography without watching any of Miyazaki movies. However, it is possible to follow Napier's important thoughts and analyses in different chapters as she does not leave them on the spot that she mentions, but nurtures them along with the new chapters, which eases the reader's experience. In the end, that is what lets us have a complete portrait of Miyazaki and making it likely to read chapters in composite order. Hence, this adds flexibility to the book as a biography. In a word, although this is a biography, at the same time, it is a film review manual of Miyazaki's. It would be an exceptional idea for cinema departments who would have Miyazaki courses, to regard students as responsible for watching a Miyazaki movie and read the related movie's chapter from Napier's book. 